\title{
Diabetes, aging and physical activity
}

\author{
Bruce Frier • Pearl Yang • Albert W. Taylor
}

Received: 8 March 2006 / Accepted: 19 July 2006 / Published online: 22 August 2006

(C) EGREPA 2006

\begin{abstract}
Diabetes mellitus (DM) is a metabolic disease affecting the regulation of insulin and glucose causing a disruption in the normal control of counterregulatory hormones and macronutrients, resulting in blood glucose accumulation. Metabolic deregulation leads to the production of noxious substances that have a particular propensity for damaging vascular and nervous structures. Physiological changes observed with aging are correlated with a concomitant increase in DM and its associated complications. Long-term complications, including peripheral and central neuropathies, micro- and macrovascular damage, retinopathy, and nephropathy are the major causes of mortality in diabetics [cardiovascular disease (CVD) being
\end{abstract}

The Canadian Centre for Activity and Aging is affiliated with St. Joseph's Health Care and The University of Western Ontario, London, Ontario, Canada.

\section{B. Frier}

School of Kinesiology, The University of Western Ontario,

London, Ontario, Canada

P. Yang

Graduate Department of Rehabilitation Science,

University of Toronto,

Toronto, Canada

A. W. Taylor

Faculty of Health Sciences, The University of Western Ontario,

London, Ontario, Canada

\section{A. W. Taylor}

Faculty of Medicine and Dentistry,

The University of Western Ontario,

London, Ontario, Canada

\author{
A. W. Taylor $(\square)$ \\ The Canadian Centre for Activity and Aging, \\ London, Ontario, Canada \\ e-mail: ataylor2@uwo.ca
}

the primary complication causing death in this population]. All-cause mortality is three to four times greater in the DM population; hence, management of DM is of timely importance, particularly with a projected prevalence increase of $134 \%$ within the next 25 years among individuals over the age of 65 years. Exercise modalities, including endurance and resistance training, were employed to improve glycemic/metabolic control and to ameliorate the progression of DM-related complications. Several risk factors, including glucose levels, blood pressure, lipid/ cholesterol profile, and BMI, are reportedly improved with these modes of exercise. However, not all studies demonstrate an improvement in risk factors, but consistently note improvement in complications and a reduction of DM incidence. There is convincing evidence that exercise, with or without specific improvements to traditional DM-related risk factors, is an effective therapy for the management of DM.

Keywords Exercise - Diabetes mellitus · Type 1 - Type 2 . Diabetes complications

\section{Introduction}

Diabetes mellitus (DM) is a metabolic pathology characterized by systemic circulatory glucose accrual, accompanied by diminishing cellular glucose uptake and metabolism. Diabetic metabolism is also evidenced by elevated counterregulatory hormones, which alters lipid metabolism and increases protein catabolism [34]. Sequelae of diabetes may include microvascular complications involving retinopathy, nephropathy, and neuropathy (distal symmetric polyneuropathy and autonomic neuropathy), and macrovascular complications culminating in coronary ar- 
tery disease. All-cause mortality is three to four times greater in patients with DM, with CVD accounting for the majority of deaths [93]. The senior population demonstrates a particular susceptibility to DM with a prevalence rate of more than half of all DM cases. With one in five seniors suffering from DM and the deleterious impairments attributed to its pathophysiology, a clear need for treatment and prevention is evident in this growing population. In 2000, the World Health Organization [106] estimated 177 million people suffered from DM. This was a $31 \%$ increase over 5 years, up from 135 million in 1995, and an astonishing $490 \%$ increase over the 1985 estimate of 30 million. The WHO projects 350 million people will suffer from diabetes by 2030 , and that DM may account for $\sim 9 \%$ of the total global causes of death [107].

DM is one of the most extensively studied pathologies, spanning centuries. Moreover, the observation that DM was a condition that indicated elevated glucose in urine led to the recommendation, over 2000 years ago, that exercise be used as a treatment [96]. The present review is not comprehensive, but will attempt to delineate some of the current perspectives on DM and will focus on the numerous physiological effects of DM and the potential for aerobic and resistance exercise to ameliorate and prevent the disease and its various accompanying pestilence within the senior demographic.

\section{Diabetes and aging}

Age-associated decline of personal vitality is generally accepted as a congenital axiom. Increased susceptibility to disease with increasing age is likewise axiomatic. Hence, age-associated physical discompositions, such as DM, heart disease, cancer, and stroke, ranging in degree from asymptomatic to death, may be perceived as immutable and intrinsically human. Comorbidity increases with age (from $\sim 35 \%$ of patients over 65 to $\sim 70 \%$ of patients over 80 ), as does the cost of treating patients who present with comorbidity [35]. In addition, comorbidity leads to an underreporting of deaths attributed to DM, as fatal events attributed to heart disease and stroke, for example, may not be ascribed to DM. Not surprisingly, decreased life expectancy of $\sim 4$ years among individuals diagnosed with DM aged 65-74 was reported [40]. The fact that all-cause mortality is three to four times greater in the DM population attests to its principal role in the lives of seniors. Not only does this amount to massive health care expenditures, but also represents a significant individual financial burden (direct and indirect costs totaling $\sim 132$ billion US dollars or $\sim 111$ billion euros in 2002 in the United States [46]). It is predicted that by the year 2030 the number of individuals over 65 who suffer from DM will increase by 134\%. The progressive nature of DM suggests that the more senior elderly demographic will suffer; between the years 2000 and 2050 the largest increase in DM prevalence is predicted to be among the elderly with the more represented senior demographic being above 75 years $(271 \%$ increase in women and $437 \%$ increase in men) [12]. The prevalence of DM in adults older than 60 years is estimated at $25 \%$ [41].

Imperative to a full account of the impact of accumulating comorbid infirmities, in addition to recognizing the direct metabolic stress of DM, is accounting for the potential for a given intervention to affect the progress and manifestation of the disease. For example, aging is associated with a mortality-related decline in muscle strength [80], a decline in muscle mass [17], decreased oxygen consumption capacity $\left(\mathrm{VO}_{2 \max }\right)$, and a concomitant increase in fat mass [86], along with increased disability [10]. DM is coincidently related to increased adiposity [5], decreased muscle mass [94], and an elevated waist circumference (associated with both DM [79] and metabolic syndrome [59]). Curiously, DM is also associated with altered mitochondrial function relative to normal individuals, suggesting diminished $\mathrm{VO}_{2 \max }$, and exercise capacity associated with DM may be related to a unique mitochondrial phenotype [68]. Therefore, it is logical to propose that therapies aimed at reducing these age-related anthropomorphic and physiological changes (for example, via exercise intervention) may provide a stimulus, which is able to reverse or prevent age- and disuse-associated physiological changes and, thereby, reduce DM and its comorbidities. However, aging may also be inherently associated with progressive physiological changes, including those leading to an increased incidence of DM, which may remain unaffected by exercise (reviewed by Degens and Alway [26] and Karakelides and Sreekumaran Nair [58]). In light of the predictive statistics for DM and the economic and personal cost of the disease, it seems an intuitive responsibility to seek out etiologies and treatment for this sweeping threat.

\section{DM symptoms}

Primarily, DM is a metabolic disorder that manifests through its varied effects on levels of circulatory and intracellular energy substrates with the inherent characteristic of high plasma glucose levels. Individuals are considered normal with a fasting plasma glucose (FPG) of $<100 \mathrm{mg} / \mathrm{dl}(5.6 \mathrm{mmol} / \mathrm{l})$. A positive $\mathrm{DM}$ diagnosis is contingent upon obtaining a FPG level $\geq 126 \mathrm{mg} / \mathrm{dl}$ (7.0 mmol/l) [4]. This measurement must be repeated on a subsequent day to confirm the diagnosis. A casual measure (regardless of time of day or time between meals) of plasma glucose $\geq 200 \mathrm{mg} / \mathrm{dl}(11.1 \mathrm{mmol} / \mathrm{l})$ is also suspect for DM 
when combined with additional symptoms, which may include unexplained weight loss, increased appetite, frequent urination (polyuria), excessive thirst (polydipsia), blurred vision, nausea, mental confusion, and fatigue. A third test frequently employed to determine hyperglycemia is an oral glucose tolerance test (OGTT). An OGTT is the oral administration of $\sim 75 \mathrm{~g}$ of water-solubilized glucose: $2 \mathrm{~h}$ postingestion, a blood glucose $\geq 200 \mathrm{mg} / \mathrm{dl}(11.1 \mathrm{mmol} / \mathrm{l})$ is provisionally indicative of DM. The essence of these tests is to confirm consistent hyperglycemia resulting from the inability to dispose of glucose due to insulin insufficiency and/or insulin resistance and/or decreased receptor sensitivity. Therefore, any one of these tests needs to be repeated to confirm the glucose profile inherent to DM. Because hyperglycemia is a hallmark symptom of DM it may also be a monolithic miscreant singularly responsible for the multifarious maladies observed with disease progression. Indeed, insulin resistance and numerous micro- and macrovascular abnormalities can be correlated with hyperglycemia, but hyperlipidemia was also proposed as a contributor to DM-associated cellular dysfunction. Moreover, the clinical and biochemical summary list of symptoms and characteristics does not conclusively elucidate the inciting incident inevitably leading to the chronic disease. Prudence dictates and current knowledge limits us to an examination of pathophysiology and potential mechanisms of cellular injury proposed in the published literature. Ideally, examining DM symptoms and pathophysiology could expose the potential for exercise and physical activity as a therapy and method of prevention in the lives of seniors.

\section{Etiology}

Central to glucose metabolism is (1) a proportional pancreatic release of insulin that (2) effects insulin receptor agonization leading to (3) intracellular glucose transporter-4 (GLUT4) translocation resulting in (4) subsequent cellular glucose uptake. DM may be represented by impairment at all four levels of glucose metabolism. DM is generally characterized by one of two types (gestational diabetes will not be discussed and is, in all likelihood, irrelevant in this review). Primarily, DM type 1 (DM1) is the complete absence of pancreatic insulin secretion due to beta cell autoimmune destruction resulting in insufficient cellular glucose uptake. Disease progression proceeds through the inability to regulate and dispose of excess glucose and glucose by-products and via elevated catabolism and lipid metabolism. DM type 2 (DM2) typically includes relatively insufficient insulin secretion with compounded cellular insulin resistance. DM2 is represented in $90-95 \%$ of all cases of DM [4]. A common perception is that DM1 originates at the level of pancreatic function whereas DM2 originates at the level of insulin receptor function. Therefore, the former is a disease of prima organum (first organ) whereas the later is finalis portus (final port). However, this distinction may not be borne out through closer pathophysiological examination of each disease, i.e., a great similarity exists between the two disease states. Functionally, the long-term and acute complications of DM (retinopathy, nephropathy, neuropathy, CVD, ketoacidosis, hyperglycemic hyperosmolar nonketotic syndrome, and hypoglycemia) can be sequelae of either phenotype.

Beta cell dysfunction vs insulin resistance is often perceived as the pillar supporting the division between DM1 and DM2. It is generally accepted that DM1 is the result of autoimmune destruction of insulin-secreting pancreatic beta cells. Hence, a singular crime, albeit with multiple suspects, leads to DM1. It was suggested that beta cell destruction and dysfunction might be central to initiating the progression of DM2 (reviewed by Khan and Chakrabarti [62] and Rhodes [89]). An estimated 41 to 63\% lower beta cell volume was observed in lean and obese individuals with DM2, respectively [15], with a selective decrease of beta cell mass and alpha cell increase, which correlated with BMI [108].

It is not clear whether beta cell destruction is an initiating factor leading to hyperglycemia and dyslipidemia in DM2 or an increasing variable responding to hyperglycemia, dyslipidemia, and insulin resistance. For instance, intracellular palmitate was shown to directly induce insulin resistance/impaired glucose uptake by downregulating GLUT4 via protein kinase C (PKC) activation [56], indicating a possible mechanism for hyperglycemia and hyperinsulinemia, independent of beta cell function and insulin quality. Nonetheless, both hyperglycemia [71] and elevated levels of free fatty acids [45] were shown to induce beta cell destruction, although through different mechanisms. Moreover, the mechanism of free fatty acidinduced beta cell destruction appears to be different than cytokine-induced apoptosis [64], which may indicate a unique etiology for DM1 autoimmune beta cell destruction and DM2. Regardless, both DM1 and DM2 similarly present with insulin quality and secretion abnormalities [3], hyperglycemia, hyperlipidemia, and hyperglucagonemia $[9,19]$, possibly due to beta cell destruction and/or alpha and beta cell miscommunication [67].

\section{Genetics of DM}

Genetic factors exist for the development of both DM1 and DM2, although DM2 demonstrates a greater inheritability than DM1. The susceptibility of pancreatic beta cells to cytokine-, fatty acid-, glucose-, or lipoprotein-induced 
destruction may be partly genetically influenced, as the concordance (probandwise) for the DM1 phenotype in monozygotic twins was reported to be $42.9 \%$ and only $3.8 \%$ in dizygotic twins [52]. Twins (median age of 55 years) with only one member originally diagnosed with DM2 showed a concordance (pairwise) rate of $76 \%$ within 15 years of initial assessment; the additional variable of impaired glucose tolerance increased the DM2 concordance rate to $96 \%$ [76]. Although susceptibility to the disease state may be partly inheritable, there exists an undeniable link between life style and disease progression, as evidenced by the previously mentioned DM link to body compositional changes, which are correlated with behavioral activities and disease interventions, such as diet and exercise. Current abilities to control genetic susceptibility to DM are lacking. Hence, the ability to control overall exposure of the internal environment to abnormal levels of provocative substances, such as glucose and glucose byproducts, is an immediate goal of disease control and prevention.

\section{Disease progression and complications}

The clinical assessment of general exposure to glucose is accomplished by measuring glycation of the A1(c) form of hemoglobin (A1C). A nonenzymatically produced ketoamine or glycation (rather than the enzyme-induced glycosylation) accumulates on A1C over time. Measuring A1C will indicate the average exposure of hemoglobin to glucose over the $\sim 120$-day life span of the red blood cell, while principally estimating mean blood glucose over the past 30 days [78]. Clinical tests report A1C as a percentage of total glycated hemoglobin. The current standard target is an $\mathrm{A} 1 \mathrm{C}$ measurement $<7 \%$ in non-DM individuals. Although DM generally leads to A1C above 7\%, the measurement per se is not indicative of DM; rather, it is specific for exposure to high glucose, which is associated with micro- and macrovascular complications. Ergo, the American Diabetes Association (ADA) [4] does not consider an A1C measurement a definitive test for DM.

Glycemic control and the interruption of hyperglycemiainduced damage pathways have long been recognized as the most important goals of treatment; inhibition of the micro- and macrovascular damage pathways is frequently the target of DM complication intervention studies. However, not all investigations report significant benefit from interrupting the activation of these (reviewed by Khan et al. [63]) and other [28] pathways. Nonetheless, there is convincing evidence that controlling hyperglycemia and $\mathrm{A} 1 \mathrm{C}$ in DM does confer benefit and reduces micro- and macrovascular complications (reviewed by Olansky [81] and Davidson [23]). For example, [90] reported that a high level of $\mathrm{A} 1 \mathrm{C}$ was associated with carotid intima-media thickness and other CVD risk factors (e.g., lipid profile and waist circumference). In addition, the joint CanadianAmerican Diabetes Control and Complications Trial (DCCT) (the effect of intensive diabetes therapy, 1995) and the United Kingdom Prospective Diabetes Study (UKPDS) have demonstrated that glucose control leads to significant reduction in micro- and macrovascular (heart disease) complications ( $\sim 30 \%$ reduction per $1 \%$ reduction in A1C) $[24,25]$. Moreover, the ability to control DMassociated high blood pressure has also demonstrated macrovascular/cardiovascular benefit [99].

Several investigations have reported specific biochemical reactions associated with hyperglycemia that may be at the heart of vascular complications in DM (reviewed by Olansky [81]). Conformational changes to red blood cells via glycation may affect movement through the microvasculature and cause damage directly. Possible pestilent pathways include the polyol pathway [11], the advanced glycation end-product pathway [36], the diacylglycerolstimulated PKC pathway [22], and oxidative stress (reviewed by Pacher and Szabo [82]). The object of their biochemical affections appears to be the endothelium: elevated vascular permeability and basement membrane thickening related to endothelial dysfunction in DM appear to be the result of these adversarial actions (reviewed by Khan and Chakrabarti [62]). As such, latent DM-related complications, including diabetic autonomic neuropathy (sympathetic and parasympathetic nerve degeneration) and especially distal symmetric polyneuropathy (axonal degeneration causing numbness and other paresthesias, often leading to injury and infection and potentially culminating in amputation), may have a common etiology.

Each DM-related complication has unique and staid consequences. Some of the more sinister corollaries, even while manifesting obtrusively, may not always be perceived as a consequence of DM. For instance, half of all amputations are performed in individuals with DM [77]. Seniors are at exceptional risk for DM-related amputation with a threefold increase between the ages of 45-74 and a sevenfold increase for those over 75 years [88]. It was projected that up to $65 \%$ of diabetic patients will die from CVD [95]. Moreover, a four- and twofold increased risk for CVD mortality in diabetic women and men compared with nondiabetic women and men, respectively, has long been observed in the scientific community [57]. In younger individuals, the second most common cause of death is acute complications (hypoglycemia, hyperglycemic hyperosmolar nonketotic syndrome, and ketoacidosis), but this is shown to decrease with age, accounting for as little as $2 \%$ of mortality between the ages of 40 and 85 years [97]. These data suggest that the vast majority of people diagnosed with DM (including those receiving treatment) 
will die from the disease. Hence, the massive accumulation of literature over several centuries has revealed DM to be exceptionally difficult to manage, in spite of clearly delineated, partly controllable mechanisms of glucose regulation. Although DM sequelae are varied and acerbic, common etiology may provide some insight into potentially successful interventions.

\section{DM and exercise}

Physical activity and physical parameters of fitness (muscle mass, fat-free mass, strength, and maximum oxygen consumption) typically decline with age [55], but exercise demonstrates a clear capacity to improve these parameters in seniors [49]. Elderly individuals who show greater fitness levels also demonstrate fewer negative health problems [91]. A previous review has revealed an inverse linear dose-response between exercise volume and all-cause mortality [61]. Similarly, exercise was shown to reduce CVD and all-cause mortality in people with DM in an inverse dose-response manner [60]. Several extensive studies have examined the positive effects of glycemic control on health profiles in DM, including the Framingham Study [57], DCCT [25], the UKPDS [74], the Kumamoto Study [92], the Finnish Diabetes Prevention Study [69], and the Wisconsin Epidemiological Study [66] (the reader is directed to the original publications and to additional reviews [39]). The mechanisms of benefit may include (1) augmented glucose uptake, (2) improved postprandial insulin secretion, (3) lowered hepatic glucose production, (4) increased cellular respiration, (5) elevated resting metabolism via increased muscle mass, and (6) improved lipid profile. Studies examining the effect of exercise on DM in the elderly are remarkably sparse when compared with the extent of DM research in general. In addition, more exercise and diabetes researches conducted in older adults regard prevention rather than treatment. Nonetheless, effects of exercise in the elderly generally follow the same pattern as the effects seen in younger adults, including improved glycemic control, cellular respiration, strength, and blood pressure, increased muscle mass, and greater fat loss. In addition, documented improvements of glycemic control in the aforementioned studies demonstrate that benefits are conferred upon representatives of both younger adults and the senior demographic.

However, not all studies illustrate changes to known risk factors, despite an observed decrease in CVD mortality. Therefore, the protective mechanism of exercise is unclear. Nonetheless, certain variables are correlated with disease progression and therapeutic intervention, such as glycemic control, and should be considered when searching for evidence that exercise may influence disease status. For example, the UKPDS and $D C C T$ reported that a reduction of A1C of only $1 \%$ conferred significant reduction in risk of progression and the development of micro- and macrovascular complications in the entire cohort of subjects (a previous review of these studies suggested up to $\sim 30 \%$ reduction per percentage decrease of A1C [85]). Therefore, in spite of the modest number of studies specifically examining exercise-induced prevention and improvements in seniors with DM, it is important to review those studies that measured glycemia and other traditionally related variables and report any changes to DM-related complications in a multitude of study populations.

\section{Endurance exercise}

Several studies revealed a relationship between DM complications and reduced risk factors derived from endurance exercise. A recent study in an aged DM population demonstrated that 1 year of moderate-intensity aerobic exercise led to a decline in BMI, total cholesterol, triglycerides, percent body fat, waist circumference, FPG, A1C, leptin, adiponectin, and C-reactive protein [49]. The magnitude of change was similar in both the aged group and a younger cohort and the beneficial changes were suggested to be derived primarily from weight loss. Endurance exercise in DM patients was also shown to improve exercise tolerance, $\mathrm{VO}_{2 \max }, \mathrm{A} 1 \mathrm{C}(\sim 1 \%)$, in addition to improving baroreceptor sensitivity (autonomic function) [70]. Hersey et al. [44] reported increased capacity of oxygen consumption in elderly men and women (70-79 years) after 6 months of endurance training at 75 $85 \% \mathrm{VO}_{2 \max }$ three times per week.

The subjects in the study by Hersey et al. [43] demonstrated a lowered plasma insulin response to an OGTT and decreased body fat compared with control subjects. In support, Wannamethee et al. [104] reported an inverse relationship between serum insulin levels and physical activity in a prospective study involving over 5,000 individuals (age 40-59 years, employing a $\sim 17$-year follow-up) from 24 towns in England, Scotland, and Wales. These investigators also demonstrated an inverse relationship between moderate physical activities, such as sports, once a week or less and more frequent activities (walking or gardening) with CVD and DM. Rahimi et al. [87] noted that another CVD marker (C-reactive protein) was inversely related to exercise capacity in elderly subjects. These researchers also reported that low exercise capacity appeared more frequently in older individuals with DM. It is interesting to note that exercise intolerance was report- 
edly symptomatic of cardiovascular neuropathy in DM patients [103].

\section{Obesity and CVD mortality}

Not all exercise studies showed significant changes in body composition or glycemic control. Prediction of CVD mortality in diabetic patients may be better correlated to fitness. Fitness assessment of over 1,200 men with DM

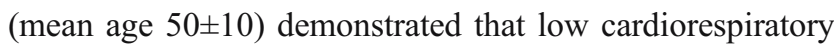
fitness and low physical activity were associated with greater all-cause mortality regardless of normally associated risk factors, such as body composition, glucose levels, and baseline CVD [105]. Similarly, in prediabetics, when baseline values for FPG and BMI were adjusted, Pan et al. [83] observed that exercise intervention was able to prevent DM by almost $50 \%$.

Even though a relationship appears between specific risk factors for both CVD mortality and diabetic complications, there appears to be a consistent effect of exercise with or without an observable change to some or all of these risk factors. A recent study of more than 2,300 individuals with both DM1 and DM2 examined the influence of cardiorespiratory fitness on CVD mortality [20]. This study noted that higher levels of fat mass and BMI were associated with lower levels of cardiorespiratory fitness. Even though there appeared to be an association between CVD mortality and traditional risk factors (high blood pressure, plasma glucose, cholesterol, and parental history), at each varying level of body composition (stratified BMI), cardiorespiratory fitness was independently predictive of CVD mortality. Hence, not all studies demonstrate a requisite exerciseinduced reduction of all risk factors to positively influence disease progression. Indeed, some trials demonstrate that the effects of exercise on DM are independent of additional risk factors.

It seems reasonable that disease control traditionally attempted to reduce risk factors associated with the multitude of complications inherent in its progression, such as by improving lipid profiles in CVD and glycemic control for micro- and macrovascular complications. As such, nutritional intervention was intuitively incorporated into patient management; hence, exercise intervention studies frequently employed both physical activity and nutritional recommendations, further confounding the effects of exercise on DM treatment and prevention. Regardless, even these studies are equivocal on the beneficial mechanism of intervention. For example, an exercise intervention with the addition of diet control revealed reduced mortality independent of any changes in glucose tolerance or BMI [32]. In contrast, a 1-year study employing moderate aerobic exercise (three to four times a week) and nutritional intervention revealed an improved cholesterol profile (elevated HDL) and a slight decrease of $\mathrm{A} 1 \mathrm{C}(\Delta=0.5 \%)$ in insulin-resistant individuals [101]. Therefore, the literature demonstrates that when aerobic exercise is incorporated into a program designed to treat or prevent DM, there is generally a reduction in complications, disease progression, and incidence of DM. However, not all studies report a reduction of risk factors associated with DM complications. Nonetheless, endurance exercise remains intimated with decreased CVD mortality and a reduction in all-cause mortality in DM, while keeping the source of its potency clandestine. Other exercise modalities employed in DM intervention studies may help uncover the consistency of exercise to alter associated risk factors, disease incidence, and progression.

\section{Resistance exercise}

For DM1 and DM2, physical activity and exercise training are beneficial in the facilitation of glucose from within the blood into muscles without the mediation of insulin, thus helping to alleviate the need for exogenous insulin or oral hypoglycemic agents [8]. Resistance training (RT) studies in diabetics started as an alternative modality of training to the precedent aerobic exercise program and were later used in combination with aerobic exercise to seek an optimal training strategy. RT in the older adult is an important training modality useful for combating age-associated, functional declines in muscle strength and endurance (associated with decreased muscle mass and resting metabolic activity) [37, 38], increased insulin resistance [84], decreased flexibility and range of motion [14], and decreased maximal aerobic capacity $[42,50,51,109,110]$. Randomized RT and combined aerobic and resistance training $(\mathrm{CT})$ studies with DM2 over the last decade have examined measures of diabetes management (glycated hemoglobin $[6,7,16,18,21,29-31,42,48,53,54,73$, 98], FPG [6, 7, 16, 18, 21, 29-31, 42, 47, 53, 73, 98], plasma insulin, and insulin sensitivity $[6,27,30,31,47,54$, 98]), anthropometrical markers of diabetic risk (BMI or weight) $[6,13,16,18,21,29-31,42,48,53,54,72,98]$, the response of cellular proteins involved in glucose regulation [27, 47], and indicators of cardiovascular risk (LDL, HDL, triglycerides, and blood pressure $[6,7,16,18$, $21,30,47,48,73])$.

\section{RT in the elderly}

Of the 13 RT studies reviewed, eight were conducted in older adults with average age between 60 and 80 years [13, 16, 27, 30, 31, 47, 48, 53]. Similarly, among the four CT 
studies, two used older adults with DM2 as their sample population [7, 21]. The most commonly measured outcomes were strength (11 out of 13 studies), glycated hemoglobin (11 out of 13), weight (11 out of 13), fasting glucose (8 out of 13), and plasma insulin (7 out of 13). It is interesting to note that despite all of the RT studies demonstrating significant increases in muscular strength, there was a low incidence of significant findings for traditional risk factors for DM-related risk factors. For instance, only four studies found significant decreases in A1C after RT [16, 18, 30, 48]; one study found a significant decrease in weight [30]; three studies found decreased fasting glucose $[6,18,53]$; and only one study found significant changes in plasma insulin levels [6]. Moreover, there were no changes in BMI $[6,29,31,42,53]$ or aerobic capacity in the studies measuring these parameters $[18,42$, 54]. It is of clinical concern that A1C was not significantly decreased in the majority of RT studies. It should be noted that those studies with significant differences in glycated hemoglobin were at least 16 weeks in duration. Within the four CT studies in diabetics considered here [7, 21, 73, 98], three found significant decreases in $\mathrm{A} 1 \mathrm{C}$ and fasting glucose $[7,73,98]$. Proportionately, the CT studies were more effective at managing glucose and significantly decreasing $\mathrm{A} 1 \mathrm{C}$.

\section{CVD risk and $\mathrm{RT}$}

As mentioned previously, decreasing the risk of cardiovascular events with exercise is an important part of diabetes management. Unfortunately, the markers of cardiovascular risk are not uniformly improved within the reviewed RT studies. Two of the five studies reported significant decreases of LDL and triglycerides posttraining [18, 48], while one of the five studies found an increase in HDL [18]. Similarly, only two studies found significant decreases in blood pressure after RT $[16,18]$. Of the CT studies reviewed, three measured cholesterol and triglycerides, while only one found significant improvement in these measures [7]. This would lead to question whether the training stimulus for the majority of these RT and CT studies was sufficient to elicit beneficial adaptations to the lipid profile and triglycerides, or whether dietary control was inadequate among subjects.

However, there is evidence that a combined endurance and RT program may be an adequate stimulus to affect CVD-related and other DM complication-related risk factors. Balducci et al. [7] were successful at significantly improving both diabetic management and cardiovascular markers. Their yearlong study, using a CT protocol with 62 subjects, found the greatest significant decreases in all examined parameters $(p<0.0001)$ of managing glucose and cardiovascular risk factors. The participants exercised aerobically for $30 \mathrm{~min}$ at $40-80 \%$ of heart rate reserve and performed three sets of 12 repetitions of resistance exercises using free weights and machines at 40 to $60 \%$ of the one-repetition maximum (1-RM). Cauza et al. [18] and Honkola et al. [48] were similarly successful in improving glucose control and cardiovascular parameters.

In summary, the effects conferred upon DM progression by endurance and resistance exercise are numerous, and myriad benefits are consistently reported. There are no enough consistent reports that indicate that the positive effects of exercise on DM are directed at any one or more associated risk factors. Nonetheless, there are no apparent reports demonstrating that a well-designed randomized control trial resulted in no reduction of incidence or microand macrovascular complications due to DM. Ergo, it is important to emphasize that exercise generally improves health and increases longevity within the diabetic population, and the lack of an unequivocally demonstrable mechanism does not diminish its inherent potency.

\section{Exercise recommendations}

Exercise potency is supported by professional organizations, such as the American College of Sports Medicine (ACSM) and the ADA. The ACSM's Position Stand on endurance exercise and DM2 [2] currently recommends that exercise should approximate the volume and intensity recommended for healthy individuals after appropriately progressing from existing levels [61]; that is, progression to moderate intensity aerobic activity leading to the expenditure of approximately $1,000 \mathrm{kcal} / \mathrm{week}$. Similarly, the ADA's Position Statement [33] indicates that previous reports showed positive effects on DM with exercise intensities between 50 and $80 \% \mathrm{VO}_{2 \max }$, three to four times a week for 30-60 min/session. Moreover, the ADA recommends exercise as a valid DM intervention in the elderly to improve fitness and insulin resistance via endurance training, and for increasing strength and muscle mass via RT.

In support, the ACSM recommends RT as part of a diabetes management strategy to help decrease the risk of associated complications [2]. The ACSM outlines a minimum frequency of twice a week; one set of 10 to 15 repetitions of 8 to 10 exercises incorporating larger muscle groups. The training protocols used within these studies have varied in the number of resistance exercises ( 3 to 10 ), repetitions ( 8 to 20 ), sets (2 to 6 ), frequency per week ( 2 to 5 ), and intensity (40 to $80 \%$ 1-RM). The RT studies showing significantly decreased A1C [16, 18, 30, 48] have used 2 to 3 bouts per week, 2 to 3 sets of 8 to 15 repetitions in 5 to 10 whole body exercises up to $85 \%$ of $1-\mathrm{RM}$ 
intensity or 10 to 15 repetition maximums for each exercise. The ACSM statement notes that greater intensity and volume of exercise may be of greater benefit for the individual. Based on the reviewed RT studies and the ACSM guidelines for intensity, this may indicate that the maximal intensity achievable, considering adherence to exercise and safety, would provide the greatest training benefit in managing diabetes.

\section{Considerations}

Individuals with DM demonstrate a repertoire of complications and conditions necessitating careful consideration before prescribing an exercise intervention. Blood glucose should be carefully monitored to avoid hypoglycemia during and after exercise. Neuropathies may prevent the detection of lacerations or pressure injuries, which may lead to infection. Hence, properly fitted footwear is imperative. Older DM patients demonstrate diminished postural control [65], which may precipitate balance-related falls. Autonomic disruption may lead to orthostatic hypotension [75], requiring care when moving from prone to supine positions during exercise. Advanced diabetic retinopathy may be exacerbated by high-intensity exercise employing the Valsalva maneuver [1]. In addition, because individuals with DM are more likely to suffer from CVD, a stress test should be performed before prescribing any exercise regimen, whether endurance or resistance. Because both endurance and resistance training are indicated and favorable in the progress and treatment of DM [102], their incorporation into a regular routine seems efficacious.

\section{Conclusion}

The ease with which pernicious diabetic complications manifest alerts the public and scientific communities to the attitudinal and physiological inherency of DM. Statistics reported by the UN [100] project that the world's population will increase from 6.5 billion today to 9.1 billion in 2050 with the senior demographic being the largest growing segment of the population. Thus, as DM prevalence grows with increasing age, the call to arms becomes decidedly urgent and bitter. Although some natural and unalterable propensity toward elevated susceptibility exists with aging, it seems unlikely that all attempts to improve our health and alter our fates will be met with an unforgiving and implacable adversary. Clearly, exercise (the very activity limited by diabetes) reveals that diabetes is a disease willing to be placated. The role of pancreatic beta cells in disease progression is becoming defined; the known biochemical pathways activated by the effects of hypergly- cemia, hyperlipidemia, and oxidative stress within the DM patient population are increasingly controllable; and dysfunctions at the level of the insulin receptor and intracellular signaling are becoming progressively delineated. The ability of exercise to improve health and confer physical fitness in a DM environment, in spite of a multitude of injurious sequelae, is evidenced by its reduction of all-cause mortality, CVD mortality, and incidence and progression of complications. Still, the volume of evidence required for our complete understanding of DM and the contribution of exercise to the attenuation of its complications is legion. The mechanistic action on DM attributable to exercise remains opaque and provocatively clandestine, but, by virtue of evidence, remains steadfastly beneficial.

Acknowledgement This study was partially funded by a grant from NSERC to D. Paterson, J. Kowalchuk, and A. W. Taylor.

\section{References}

1. Aiello LP, Cahill MT, Wong JS (2001) Systemic considerations in the management of diabetic retinopathy. Am J Ophthalmol 132:760-776

2. Albright A, Franz M, Hornsby G, Kriska A, Marrero D, Ullrich I, Verity LS (2000) American College of Sports Medicine position stand. Exercise and type 2 diabetes. Med Sci Sports Exerc 32:1345-1360

3. Alssema M, Dekker JM, Nijpels G, Stehouwer CD, Bouter LM, Heine RJ (2005) Proinsulin concentration is an independent predictor of all-cause and cardiovascular mortality: an 11-year follow-up of the Hoorn study. Diabetes Care 28:860-865

4. American Diabetes Association (2006) Diagnosis and classification of diabetes mellitus. Diabetes Care 29(Suppl 1):S43-S48

5. Anderwald C, Roden M (2004) Adipotoxicity and the insulin resistance syndrome. Pediatr Endocrinol Rev 1:310-319

6. Baldi JC, Snowling N (2003) Resistance training improves glycaemic control in obese type 2 diabetic men. Int J Sports Med 24:419-423

7. Balducci S, Leonetti F, Di Mario U, Fallucca F (2004) Is a longterm aerobic plus resistance training program feasible for and effective on metabolic profiles in type 2 diabetic patients? Diabetes Care 27:841-842

8. Barnard RJ, Jung T, Inkeles SB (1994) Diet and exercise in the treatment of NIDDM. The need for early emphasis. Diabetes Care 17:1469-1472

9. Baron AD, Schaeffer L, Shragg P, Kolterman OG (1987) Role of hyperglucagonemia in maintenance of increased rates of hepatic glucose output in type II diabetics. Diabetes 36:274-283

10. Baumgartner RN, Wayne SJ, Waters DL, Janssen I, Gallagher D, Morley JE (2004) Sarcopenic obesity predicts instrumental activities of daily living disability in the elderly. Obes Res 12:1995-2004

11. Berrone E, Beltramo E, Solimine C, Ubertalli Ape A, Porta M (2006) Regulation of intracellular glucose and polyol pathway by thiamine and benfotiamine in vascular cells cultured in high glucose. J Biol Chem 281(14):9307-9313

12. Boyle JP, Honeycutt AA, Narayan KM, Hoerger TJ, Geiss LS, Chen H, Thompson TJ (2001) Projection of diabetes burden through 2050: impact of changing demography and disease prevalence in the U.S. Diabetes Care 24:1936-1940 
13. Brandon LJ, Gaasch DA, Boyette LW, Lloyd AM (2003) Effects of long-term resistive training on mobility and strength in older adults with diabetes. J Gerontol A Biol Sci Med Sci 58:740-745

14. Brandon LJ, Boyette LW, Lloyd A, Gaasch DA (2004) Resistive training and long-term function in older adults. J Aging Phys Act 12:10-28

15. Butler AE, Janson J, Bonner-Weir S, Ritzel R, Rizza RA, Butler PC (2003) Beta-cell deficit and increased beta-cell apoptosis in humans with type 2 diabetes. Diabetes 52:102-110

16. Castaneda C, Layne JE, Munoz-Orians L, Gordon PL, Walsmith J, Foldvari M, Roubenoff R, Tucker KL, Nelson ME (2002) A randomized controlled trial of resistance exercise training to improve glycemic control in older adults with type 2 diabetes. Diabetes Care 25:2335-2341

17. Castillo EM, Goodman-Gruen D, Kritz-Silverstein D, Morton DJ, Wingard DL, Barrett-Connor E (2003) Sarcopenia in elderly men and women: the Rancho Bernardo study. Am J Prev Med 25:226-231

18. Cauza E, Hanusch-Enserer U, Strasser B, Ludvik B, MetzSchimmerl S, Pacini G, Wagner O, Georg P, Prager R, Kostner K, Dunky A, Haber P (2005) The relative benefits of endurance and strength training on the metabolic factors and muscle function of people with type 2 diabetes mellitus. Arch Phys Med Rehabil 86:1527-1533

19. Charlton MR, Nair KS (1998) Role of hyperglucagonemia in catabolism associated with type 1 diabetes: effects on leucine metabolism and the resting metabolic rate. Diabetes 47: $1748-1756$

20. Church TS, LaMonte MJ, Barlow CE, Blair SN (2005) Cardiorespiratory fitness and body mass index as predictors of cardiovascular disease mortality among men with diabetes. Arch Intern Med 165:2114-2120

21. Cuff DJ, Meneilly GS, Martin A, Ignaszewski A, Tildesley HD, Frohlich JJ (2003) Effective exercise modality to reduce insulin resistance in women with type 2 diabetes. Diabetes Care 26:2977-2982

22. Dang L, Seale JP, Qu X (2005) High glucose-induced human umbilical vein endothelial cell hyperpermeability is dependent on protein kinase $\mathrm{C}$ activation and independent of the $\mathrm{Ca}^{2+}$-nitric oxide signalling pathway. Clin Exp Pharmacol Physiol 32: $771-776$

23. Davidson JA (2004) Treatment of the patient with diabetes: importance of maintaining target $\mathrm{HbA}(1 \mathrm{c})$ levels. Curr Med Res Opin 20:1919-1927

24. DCCT Research Group (1993) The effect of intensive treatment of diabetes on the development and progression of long-term complications in insulin-dependent diabetes mellitus. The Diabetes Control and Complications Trial Research Group. N Engl J Med 329:977-986

25. DCCT Research Group (1995) Effect of intensive diabetes management on macro-vascular events and risk factors in the Diabetes Control and Complications Trial. Am J Cardiol 75:894-903

26. Degens H, Alway SE (2006) Control of muscle size during disuse, disease, and aging. Int J Sports Med 27:94-99

27. Dela F, Holten M, Juel C (2004) Effect of resistance training on $\mathrm{Na}, \mathrm{K}$ pump and $\mathrm{Na}+/ \mathrm{H}+$ exchange protein densities in muscle from control and patients with type 2 diabetes. Pflugers Arch 447:928-933

28. Duan W, Paka L, Pillarisetti S (2005) Distinct effects of glucose and glucosamine on vascular endothelial and smooth muscle cells: evidence for a protective role for glucosamine in atherosclerosis. Cardiovasc Diabetol 4:16

29. Dunstan DW, Puddey IB, Beilin LJ, Burke V, Morton AR, Stanton KG (1998) Effects of a short-term circuit weight training program on glycaemic control in NIDDM. Diabetes Res Clin Pract 40:53-61

30. Dunstan DW, Daly RM, Owen N, Jolley D, De Courten M, Shaw J, Zimmet P (2002) High-intensity resistance training improves glycemic control in older patients with type 2 diabetes. Diabetes Care 25:1729-1736

31. Dunstan DW, Daly RM, Owen N, Jolley D, Vulikh E, Shaw J, Zimmet P (2005) Home-based resistance training is not sufficient to maintain improved glycemic control following supervised training in older individuals with type 2 diabetes. Diabetes Care 28:3-9

32. Eriksson KF, Lindgarde F (1998) No excess 12-year mortality in men with impaired glucose tolerance who participated in the Malmo Preventive Trial with diet and exercise. Diabetologia 41:1010-1016

33. Expert Committee on the Diagnosis and Classification of Diabetes Mellitus (2002) American Diabetes Association: clinical practice recommendations 2002. Diabetes Care 25(Suppl 1): S1-S147

34. Felig P, Wahren J, Sherwin R, Palaiologos G (1977) Amino acid and protein metabolism in diabetes mellitus. Arch Intern Med 137:507-513

35. Fried LP, Ferrucci L, Darer J, Williamson JD, Anderson G (2004) Untangling the concepts of disability, frailty, and comorbidity: implications for improved targeting and care. J Gerontol A Biol Sci Med Sci 59:255-263

36. Friedman EA (1999) Advanced glycosylated end products and hyperglycemia in the pathogenesis of diabetic complications. Diabetes Care 22(Suppl 2):B65-B71

37. Frontera WR, Hughes VA, Lutz KJ, Evans WJ (1991) A crosssectional study of muscle strength and mass in 45- to 78-yr-old men and women. J Appl Physiol 71:644-650

38. Frontera WR, Hughes VA, Fielding RA, Fiatarone MA, Evans WJ, Roubenoff R (2000) Aging of skeletal muscle: a 12-yr longitudinal study. J Appl Physiol 88:1321-1326

39. Gaster B, Hirsch IB (1998) The effects of improved glycemic control on complications in type 2 diabetes. Arch Intern Med 158:134-140

40. Gu K, Cowie CC, Harris MI (1998) Mortality in adults with and without diabetes in a national cohort of the U.S. population, 1971-1993. Diabetes Care 21:1138-1145

41. Harris MI, Flegal KM, Cowie CC, Eberhardt MS, Goldstein DE, Little RR, Wiedmeyer HM, Byrd-Holt DD (1998) Prevalence of diabetes, impaired fasting glucose, and impaired glucose tolerance in U.S. adults. The Third National Health and Nutrition Examination Survey, 1988-1994. Diabetes Care 21:518-524

42. Herriott MT, Colberg SR, Parson HK, Nunnold T, Vinik AI (2004) Effects of 8 weeks of flexibility and resistance training in older adults with type 2 diabetes. Diabetes Care 27: 2988-2989

43. Hersey WC,3rd, Graves JE, Pollock ML, Gingerich R, Shireman RB, Heath GW, Spierto F, McCole SD, Hagberg JM (1994) Endurance exercise training improves body composition and plasma insulin responses in 70- to 79-year-old men and women. Metabolism 43:847-854

44. Hersey WC III, Graves JE, Pollock ML, Gingerich R, Shireman RB, Heath GW, Spierto F, McCole SD, Hagberg JM (1994) Endurance exercise training improves body composition and plasma insulin responses in 70- to 79-year-old men and women. Metabolism 43:847-854

45. Higa M, Zhou YT, Ravazzola M, Baetens D, Orci L, Unger RH (1999) Troglitazone prevents mitochondrial alterations, beta cell destruction, and diabetes in obese prediabetic rats. Proc Natl Acad Sci U S A 96:11513-11518

46. Hogan P, Dall T, Nikolov P (2003) American Diabetes Association. Economic costs of diabetes in the US in 2002. Diabetes Care 26:917-932 
47. Holten MK, Zacho M, Gaster M, Juel C, Wojtaszewski JF, Dela F (2004) Strength training increases insulin-mediated glucose uptake, GLUT4 content, and insulin signaling in skeletal muscle in patients with type 2 diabetes. Diabetes 53:294-305

48. Honkola A, Forsen T, Eriksson J (1997) Resistance training improves the metabolic profile in individuals with type 2 diabetes. Acta Diabetol 34:245-248

49. Hsieh CJ, Wang PW (2005) Effectiveness of weight loss in the elderly with type 2 diabetes mellitus. J Endocrinol Invest 28:973-977

50. Hughes VA, Frontera WR, Wood M, Evans WJ, Dallal GE, Roubenoff R, Fiatarone Singh MA (2001) Longitudinal muscle strength changes in older adults: influence of muscle mass, physical activity, and health. J Gerontol A Biol Sci Med Sci 56: B209-B217

51. Hughes VA, Frontera WR, Roubenoff R, Evans WJ, Singh MA (2002) Longitudinal changes in body composition in older men and women: role of body weight change and physical activity. Am J Clin Nutr 76:473-481

52. Hyttinen V, Kaprio J, Kinnunen L, Koskenvuo M, Tuomilehto J (2003) Genetic liability of type 1 diabetes and the onset age among 22,650 young Finnish twin pairs: a nationwide follow-up study. Diabetes 52:1052-1055

53. Ibanez J, Izquierdo M, Arguelles I, Forga L, Larrion JL, GarciaUnciti M, Idoate F, Gorostiaga EM (2005) Twice-weekly progressive resistance training decreases abdominal fat and improves insulin sensitivity in older men with type 2 diabetes. Diabetes Care 28:662-667

54. Ishii T, Yamakita T, Sato T, Tanaka S, Fujii S (1998) Resistance training improves insulin sensitivity in NIDDM subjects without altering maximal oxygen uptake. Diabetes Care 21:1353-1355

55. Jackson AS, Beard EF, Wier LT, Ross RM, Stuteville JE, Blair SN (1995) Changes in aerobic power of men, ages 25-70 yr. Med Sci Sports Exerc 27:113-120

56. Jove M, Planavila A, Sanchez RM, Merlos M, Laguna JC, Vazquez-Carrera M (2006) Palmitate induces tumor necrosis factor-alpha expression in $\mathrm{C} 2 \mathrm{C} 12$ skeletal muscle cells by a mechanism involving protein kinase $\mathrm{C}$ and nuclear factorkappaB activation. Endocrinology 147:552-561

57. Kannel WB, McGee DL (1979) Diabetes and cardiovascular disease. The Framingham study. JAMA 241:2035-2038

58. Karakelides H, Sreekumaran Nair K (2005) Sarcopenia of aging and its metabolic impact. Curr Top Dev Biol 68:123-148

59. Katzmarzyk PT, Janssen I, Ross R, Church TS, Blair SN (2006) The importance of waist circumference in the definition of metabolic syndrome: prospective analyses of mortality in men. Diabetes Care 29:404-409

60. Kelley DE, Goodpaster BH (2001) Effects of exercise on glucose homeostasis in type 2 diabetes mellitus. Med Sci Sports Exerc 33:S495-501; discussion S528-S529

61. Kesaniemi YK, Danforth E,Jr, Jensen MD, Kopelman PG, Lefebvre P, Reeder BA (2001) Dose-response issues concerning physical activity and health: an evidence-based symposium. Med Sci Sports Exerc 33:S351-S358

62. Khan ZA, Chakrabarti S (2003) Endothelins in chronic diabetic complications. Can J Physiol Pharmacol 81:622-634

63. Khan ZA, Farhangkhoee H, Chakrabarti S (2006) Towards newer molecular targets for chronic diabetic complications. Curr Vasc Pharmacol 4:45-57

64. Kharroubi I, Ladriere L, Cardozo AK, Dogusan Z, Cnop M, Eizirik DL (2004) Free fatty acids and cytokines induce pancreatic beta-cell apoptosis by different mechanisms: role of nuclear factor-kappaB and endoplasmic reticulum stress. Endocrinology 145:5087-5096
65. Kim BJ, Robinson CJ (2005) Postural control and detection of slip/fall initiation in the elderly population. Ergonomics 48:1065-1085

66. Klein R, Klein BE, Moss SE (1989) The Wisconsin epidemiological study of diabetic retinopathy: a review. Diabetes Metab Rev 5:559-570

67. Koeslag JH, Saunders PT, Terblanche E (2003) A reappraisal of the blood glucose homeostat which comprehensively explains the type 2 diabetes mellitus-syndrome $\mathrm{X}$ complex. J Physiol 549:333-346

68. Lamson DW, Plaza SM (2002) Mitochondrial factors in the pathogenesis of diabetes: a hypothesis for treatment. Altern Med Rev 7:94-111

69. Lindstrom J, Louheranta A, Mannelin M, Rastas M, Salminen V, Eriksson J, Uusitupa M, Tuomilehto J, Finnish Diabetes Prevention Study Group (2003) The Finnish Diabetes Prevention Study (DPS): lifestyle intervention and 3-year results on diet and physical activity. Diabetes Care 26:3230-3236

70. Loimaala A, Huikuri HV, Koobi T, Rinne M, Nenonen A, Vuori I (2003) Exercise training improves baroreflex sensitivity in type 2 diabetes. Diabetes 52:1837-1842

71. Maedler K, Sergeev P, Ris F, Oberholzer J, Joller-Jemelka HI, Spinas GA, Kaiser N, Halban PA, Donath MY (2002) Glucoseinduced beta cell production of IL-1beta contributes to glucotoxicity in human pancreatic islets. J Clin Invest 110:851-860

72. Maiorana A, O'Driscoll G, Cheetham C, Dembo L, Stanton K, Goodman C, Taylor R, Green D (2001) The effect of combined aerobic and resistance exercise training on vascular function in type 2 diabetes. J Am Coll Cardiol 38:860-866

73. Maiorana A, O'Driscoll G, Goodman C, Taylor R, Green D (2002) Combined aerobic and resistance exercise improves glycemic control and fitness in type 2 diabetes. Diabetes Res Clin Pract 56:115-123

74. Manley S (2003) Haemoglobin A1c - a marker for complications of type 2 diabetes: the experience from the UK Prospective Diabetes Study (UKPDS). Clin Chem Lab Med 41:1182-1190

75. Maser RE, Lenhard MJ (2005) Cardiovascular autonomic neuropathy due to diabetes mellitus: clinical manifestations, consequences, and treatment. J Clin Endocrinol Metab 90:5896-5903

76. Medici F, Hawa M, Ianari A, Pyke DA, Leslie RD (1999) Concordance rate for type II diabetes mellitus in monozygotic twins: actuarial analysis. Diabetologia 42:146-150

77. Morris AD, McAlpine R, Steinke D, Boyle DI, Ebrahim AR, Vasudev N, Stewart CP, Jung RT, Leese GP, MacDonald TM, Newton RW (1998) Diabetes and lower-limb amputations in the community. A retrospective cohort study. DARTS/MEMO Collaboration. Diabetes Audit and Research in Tayside Scotland/Medicines Monitoring Unit. Diabetes Care 21:738-743

78. Mortensen HB, Volund A (1988) Application of a biokinetic model for prediction and assessment of glycated haemoglobins in diabetic patients. Scand J Clin Lab Invest 48:595-602

79. Mosca L, Edelman D, Mochari H, Christian AH, Paultre F, Pollin I (2006) Waist circumference predicts cardiometabolic and global Framingham risk among women screened during National Woman's Heart Day. J Womens Health (Larchmt) 15:24-34

80. Newman AB, Kupelian V, Visser M, Simonsick EM, Goodpaster BH, Kritchevsky SB, Tylavsky FA, Rubin SM, Harris TB (2006) Strength, but not muscle mass, is associated with mortality in the health, aging and body composition study cohort. J Gerontol A Biol Sci Med Sci 61:72-77

81. Olansky L (2004) Advances in diabetes for the millennium: chronic microvascular complications of diabetes. MedGenMed 6:14

82. Pacher P, Szabo C (2005) Role of poly(ADP-ribose) polymerase1 activation in the pathogenesis of diabetic complications: 
endothelial dysfunction, as a common underlying theme. Antioxid Redox Signal 7:1568-1580

83. Pan XR, Li GW, Hu YH, Wang JX, Yang WY, An ZX, Hu ZX, Lin J, Xiao JZ, Cao HB, Liu PA, Jiang XG, Jiang YY, Wang JP, Zheng H, Zhang H, Bennett PH, Howard BV (1997) Effects of diet and exercise in preventing NIDDM in people with impaired glucose tolerance. The Da Qing IGT and Diabetes Study. Diabetes Care 20:537-544

84. Petersen KF, Befroy D, Dufour S, Dziura J, Ariyan C, Rothman DL, DiPietro L, Cline GW, Shulman GI (2003) Mitochondrial dysfunction in the elderly: possible role in insulin resistance. Science 300:1140-1142

85. Phillips PJ, Phillipov G (2005) A1C-frequently asked questions. Aust Fam Physician 34:663-667

86. Raguso CA, Kyle U, Kossovsky MP, Roynette C, PaoloniGiacobino A, Hans D, Genton L, Pichard C (2005) A 3-year longitudinal study on body composition changes in the elderly: role of physical exercise. Clin Nutr 25(4):573-580

87. Rahimi K, Secknus MA, Adam M, Hayerizadeh BF, Fiedler M, Thiery J, Schuler G (2005) Correlation of exercise capacity with high-sensitive C-reactive protein in patients with stable coronary artery disease. Am Heart J 150:1282-1289

88. Reiber GE (1993) Epidemiology of the diabetic foot. In: Levin ME, O'Neal LW, Bowker JH (eds) The diabetic foot, 5th edn. Mosby Year Book, St. Louis, pp 1-5

89. Rhodes CJ (2005) Type 2 diabetes - a matter of beta-cell life and death? Science 307:380-384

90. Selvin E, Coresh J, Golden SH, Boland LL, Brancati FL, Steffes MW (2005) Atherosclerosis risk in communities study. Glycemic control, atherosclerosis, and risk factors for cardiovascular disease in individuals with diabetes: the atherosclerosis risk in communities study. Diabetes Care 28:1965-1973

91. Shephard RJ (1997) Impact of regular physical activity on ageassociated changes in physiological systems. In: Shephard RJ (ed) Aging, physical activity, and health. Human Kinetics, Windsor, pp 139-197

92. Shichiri M, Kishikawa H, Ohkubo Y, Wake N (2000) Longterm results of the Kumamoto study on optimal diabetes control in type 2 diabetic patients. Diabetes Care 23(Suppl 2): B21-B29

93. Soedamah-Muthu SS, Fuller JH, Mulnier HE, Raleigh VS, Lawrenson RA, Colhoun HM (2006) All-cause mortality rates in patients with type 1 diabetes mellitus compared with a nondiabetic population from the UK general practice research database, 1992-1999. Diabetologia 49(4):660-666

94. Stewart KJ, Bacher AC, Turner K, Lim JG, Hees PS, Shapiro EP, Tayback M, Ouyang P (2005) Exercise and risk factors associated with metabolic syndrome in older adults. Am J Prev Med 28:9-18

95. Stone PH, Muller JE, Hartwell T, York BJ, Rutherford JD, Parker CB, Turi ZG, Strauss HW, Willerson JT, Robertson T (1989) The effect of diabetes mellitus on prognosis and serial left ventricular function after acute myocardial infarction: contribution of both coronary disease and diastolic left ventricular dysfunction to the adverse prognosis. The MILIS Study Group. J Am Coll Cardiol 14:49-57

96. Sushruta SC (1938) Anonymous Vaidya Jadavaji Trikamji Acharia, 3rd edn. Nirnyar Sagar Press, Bombay

97. Swerdlow AJ, Jones ME (1996) Mortality during 25 years of follow-up of a cohort with diabetes. Int J Epidemiol 25:1250-1261

98. Tokmakidis SP, Zois CE, Volaklis KA, Kotsa K, Touvra AM (2004) The effects of a combined strength and aerobic exercise program on glucose control and insulin action in women with type 2 diabetes. Eur J Appl Physiol 92:437-442

99. UKPDS Group (1998) Tight blood pressure control and risk of macro-vascular and micro-vascular complications in type 2 diabetes: UKPDS 38. UK Prospective Diabetes Study Group. BMJ 317:703-713

100. United Nations (2005) World population prospects: the 2004 revision. Population Newsletter, no. 79. Population Division Department of Economic and Social Affairs

101. Uusitupa MI (1996) Early lifestyle intervention in patients with non-insulin-dependent diabetes mellitus and impaired glucose tolerance. Ann Med 28:445-449

102. Venojarvi M, Puhke R, Hamalainen H, Marniemi J, Rastas M, Rusko H, Nuutila P, Hanninen O, Aunola S (2005) Role of skeletal muscle-fibre type in regulation of glucose metabolism in middle-aged subjects with impaired glucose tolerance during a long-term exercise and dietary intervention. Diabetes Obes Metab 7:745-754

103. Vinik AI, Freeman R, Erbas T (2003) Diabetic autonomic neuropathy. Semin Neurol 23:365-372

104. Wannamethee SG, Shaper AG, Alberti KG (2000) Physical activity, metabolic factors, and the incidence of coronary heart disease and type 2 diabetes. Arch Intern Med 160:2108-2116

105. Wei M, Gibbons LW, Kampert JB, Nichaman MZ, Blair SN (2000) Low cardiorespiratory fitness and physical inactivity as predictors of mortality in men with type 2 diabetes. Ann Intern Med 132:605-611

106. World Health Organization (2002) Diabetes mellitus. Fact sheet no. 138

107. World Health Organization (2002) Diabetes mellitus: the cost of diabetes. Fact sheet no. 236

108. Yoon KH, Ko SH, Cho JH, Lee JM, Ahn YB, Song KH, Yoo SJ, Kang MI, Cha BY, Lee KW, Son HY, Kang SK, Kim HS, Lee IK, Bonner-Weir S (2003) Selective beta-cell loss and alpha-cell expansion in patients with type 2 diabetes mellitus in Korea. J Clin Endocrinol Metab 88:2300-2308

109. Young A, Stokes M, Crowe M (1984) Size and strength of the quadriceps muscles of old and young women. Eur J Clin Invest 14:282-287

110. Young A, Stokes M, Crowe M (1985) The size and strength of the quadriceps muscles of old and young men. Clin Physiol 5:145-154 